Check for updates

Cite this: Chem. Sci., 2019, 10, 5634

๑ All publication charges for this article have been paid for by the Royal Society of Chemistry

Received 14th February 2019

Accepted 27th April 2019

DOI: $10.1039 / \mathrm{c} 9 \mathrm{sc} 00768 \mathrm{~g}$

rsc.li/chemical-science

\section{Automated glycan assembly of Lewis type I and II oligosaccharide antigens $\uparrow$}

\author{
Mónica Guberman, $\star^{\text {ab }}$ Maria Bräutigam $\ddagger^{a}$ and Peter H. Seeberger (D) *ab \\ Human blood group related glycan antigens are fucosylated (neo-)lactoseries oligosaccharides that play \\ crucial roles in pathogenic processes. Lewis type-II-chain antigens mark the surface of cancer cells, but \\ are also mediators of bacterial infections. To investigate the biological roles of Lewis type glycans a host \\ of synthetic approaches has been developed. Here, we illustrate how automated glycan assembly (AGA) \\ using a set of six monosaccharide building blocks provides quick access to a series of more than ten \\ defined Lewis type-I and type-II antigens, including $L e^{x}, L e^{y}, L e^{a}, L e^{b}$ and $K H-1$. Glycans with up to three \\ $\alpha$-fucose branches were assembled following a strictly linear approach and obtained in excellent \\ stereoselectivity and purity.
}

\section{Introduction}

Lewis antigens are lacto- or neolacto-series oligosaccharides that are commonly found as part of glycoproteins or glycolipids on the eukaryotic cell surface..$^{1-3}$ These antigens are related to the ABO blood-group system and are implicated in developmental processes, reproductive physiology, oncogenic transformations, cell-cell communication and pathogen-host interactions. ${ }^{2,4-11}$ Lewis lacto-series (type-I-chain) glycans 1-3 are fucosylated versions of a lactotetraosyl $\left(\mathrm{Lc}_{4}\right)$ core 4 . Similarly, Lewis neolacto (type-II-chain) antigens 5-7 result from fucosylation of neolactotetraosyl ( $\mathrm{nLc}_{4}$ ) core 8 (Fig. 1A).

While the importance of blood group antigens for blood transfusions is established, their involvement in infectious diseases and cancer development is still emerging. Lewis ${ }^{\mathrm{b}}\left(\mathrm{Le}^{\mathrm{b}}\right)$ 3 expressed on gastric epithelium is the receptor for Helicobacter pylori, the cause chronic gastritis and peptic ulcers. ${ }^{6}$ Type-II chain analogue Lewis $^{y}\left(\mathrm{Le}^{\mathrm{y}}\right) 7$ is a tumor-associated carbohydrate antigen (TACA), that is overexpressed on the cell surface of several types of cancer. ${ }^{12-14} \mathrm{Le}^{\mathrm{b}}$ and $\mathrm{Le}^{\mathrm{y}}$ vary minimally in the regiochemistry of the glycosidic linkage in the terminal $N$ acetyllactosamine subunit of the $\mathrm{Lc}_{4}(\mathbf{4}) / \mathrm{nLc}_{4}(\mathbf{8})$ core $(\beta(1-3) v s$. $\beta(1-4)$, respectively). Extended chain versions of Lewis antigens such as $\mathrm{Le}^{\mathrm{x}}$ dimer $\left(\mathrm{Le}^{\mathrm{x}}-\mathrm{Le}^{\mathrm{x}}, 9\right)$ and $\mathrm{KH}-1\left(\mathrm{Le}^{\mathrm{x}}-\mathrm{Le}^{\mathrm{y}}, \mathbf{1 0}\right)$ are attractive targets for tumor immunotherapy (Fig. 1B). These TACAs are overexpressed in colorectal cancer and overcome the

${ }^{a}$ Department of Biomolecular Systems, Max Planck Institute of Colloids and Interfaces, Am Mühlenberg 1, 14476 Potsdam, Germany. E-mail: Peter.Seeberger@mpikg.mpg.de ${ }^{b}$ Department of Chemistry and Biochemistry, Freie Universität Berlin, Arnimalle 22, 14195 Berlin, Germany

$\dagger$ Electronic supplementary information (ESI) available: Full experimental information, HPLC chromatograms for AGA syntheses, ${ }^{1} \mathrm{H},{ }^{13} \mathrm{C}$, COSY and HSQC NMR spectra of all new compounds. See DOI: 10.1039/c9sc00768g

\$ These authors contributed equally. low immunogenicity observed in human trials when using shorter antigens such as $\mathrm{Le}^{\mathrm{y}} \cdot{ }^{\mathbf{1 5 - 2 0}}$

Synthetic access to oligosaccharide antigens is essential as isolation of useful amounts of pure glycans from biological sources is difficult. ${ }^{21,22}$ Numerous syntheses of Lewis antigens that serve as tools e.g. for immunotherapy ${ }^{\mathbf{2 0 , 2 3 , 2 4}}$ have been reported, including solution-phase, solid-phase and automated syntheses..$^{1925-28}$ Despite the structural similarity of Lewis antigens, typically total syntheses produce single structures. ${ }^{29-31}$

Here, we present a general method to assemble the entire class of Lewis antigens. The lacto- and neolacto-series target molecules differ in three structural aspects: the presence or absence of fucose on the terminal galactose; the presence or absence of fucose on GlcNAc, and the $\beta(1-3)$ or $\beta(1-4)$ linkage in the lactosamine subunit. The logic of automated glycan assembly (AGA) is based on the selection of a minimum set of monosaccharide building blocks to assemble all targeted glycans via a linear glycosylation and deprotection sequence. ${ }^{32,33}$ AGA reduces the synthesis time considerably $y^{\mathbf{3 4}, 35}$ and facilitates the assembly of large, complex antigens such as $\mathbf{9}$ or $\mathbf{1 0} .^{36}$ Access to lacto- and neolacto-series variants that carry a linker for conjugation allows them to be used as tools for diverse biological applications, in particular those where minor structural differences between type-I- and type-II-chain antigens, ${ }^{37}$ are concerned.

\section{Results and discussion}

"Approved building blocks", referring to monomers that can be prepared in large amounts, are shelf stable and upon activation result in reliable and selective glycosidic bond formation, are key to AGA. ${ }^{35}$ The five monosaccharide building blocks 11-15, which suffice to access all Le type-II blood group related antigen targets (Fig. 2), are either commercially available or were 
A

Type-I Chain

Lacto series
Type-Il Chain

Neolacto series
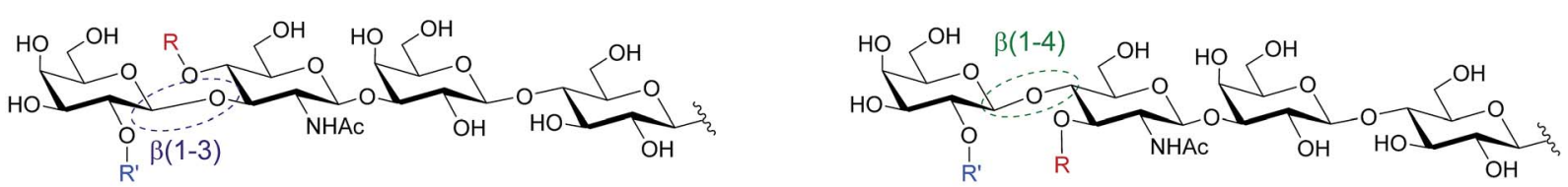

$\begin{array}{ll}1 \mathrm{R}=\mathrm{H}, \mathrm{R}^{\prime}=\alpha-\mathrm{L}-\mathrm{Fuc} & \mathrm{H} \text { antigen (I) } \\ 2 \mathrm{R}=\alpha-\text { L-Fuc, } \mathrm{R}^{\prime}=\mathrm{H} & \mathrm{Le}^{\mathrm{a}} \\ 3 \mathrm{R}=\mathrm{R}^{\prime}=\alpha-\mathrm{L}-\text { Fuc } & \mathrm{Le}^{\mathrm{b}} \\ 4 \mathrm{R}=\mathrm{R}^{\prime}=\mathrm{H} & \mathrm{Lc}_{4}\end{array}$

$R, R^{\prime}=\mathrm{H}$ or $\begin{array}{ll}5 \mathrm{R}=\mathrm{H}, \mathrm{R}^{\prime}=\alpha-\mathrm{L}-\mathrm{Fuc} & \mathrm{H} \text { antigen (II) } \\ 6 \mathrm{R}=\alpha-\mathrm{L}-\text { Fuc }, \mathrm{R}^{\prime}=\mathrm{H} & \mathrm{Le}^{\mathrm{x}} \\ 7 \mathrm{R}=\mathrm{R}^{\prime}=\alpha-\mathrm{L}-\text { Fuc } & \mathrm{Le}^{\mathrm{y}} \\ 8 \mathrm{R}=\mathrm{R}^{\prime}=\mathrm{H} & \mathrm{nLc}_{4}\end{array}$

B

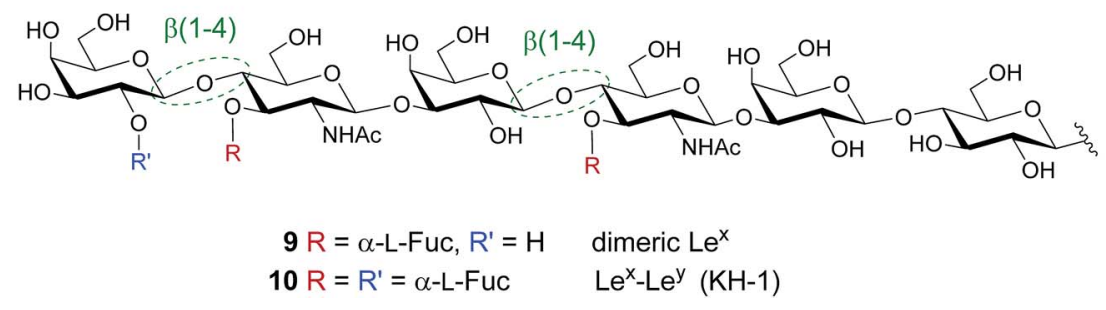

Fig. 1 (A) Lewis type-I and type-II chain blood group related oligosaccharide antigens and (B) dimeric structures of the Lewis type-II chain that are exclusively found on cancer tissue.
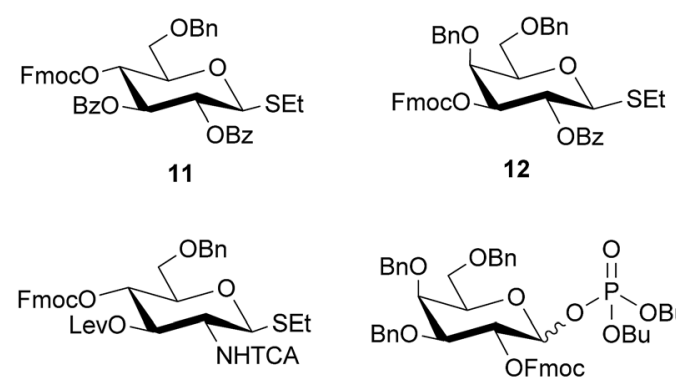

13

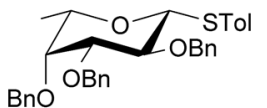

15

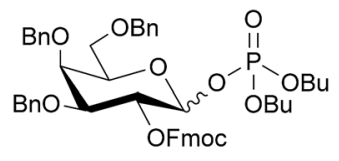

14

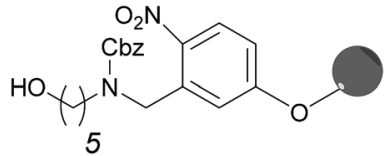

16
Fig. 2 Solid support and building blocks used for the AGA of protected Lewis type-II chain oligosaccharides.

synthesized in multi-gram scale in a few steps starting from commercial intermediates (see $\mathrm{ESI}_{\dagger}^{\dagger}$ for details). Hydroxyl groups of building blocks 11-14 that engage in chain elongation are temporarily protected as 9-fluorenylmethoxycarbonyl (Fmoc) carbonates that are stable under the acidic glycosylation conditions, but can be easily removed under mild basic conditions. Levulinoyl ester (Lev) marks the C3-hydroxyl in glucosamine (GlcN) $\mathbf{1 3}$ as orthogonal temporary protecting group as illustrated for AGA before. ${ }^{38,39}$ Benzyl ether (Bn) and benzoyl esters (Bz), when $\mathrm{C} 2$ participation is needed, are used as permanent protecting groups. The amine of GlcN 13 was protected as an $N$-trichloroacetyl (TCA) group to ensure $\beta$-selectivity. The permanent protecting groups should be removed after AGA and light-induced cleavage of the solid support by methanolysis (Bz) and hydrogenolysis (TCA and Bn). Ready synthetic access and high stability, prompted us to use thioglycosides as anomeric leaving groups of all building blocks except galactose 14. The $\mathrm{C} 2-\mathrm{OFmoc}$ in 14 resulted in low stereoselectivity for the thioglycoside, while the dibutyl phosphate building block ensured excellent stereoselectivity (see ESI $\dagger$ ). The selectivity differences may be a result of a change in solvent used during the glycosylation, since dioxane is added to ensure solubility of NIS/TfOH required for thioglycoside activation. Dioxane coordinates the $\beta$-face of the oxocarbenium ion that forms during glycosylation and favors the formation of the $\alpha$ glycosylation product. ${ }^{40}$ Dibutyl phosphates can be activated by TMSOTf in DCM, hence solvent coordination does not influence the reaction.

Before synthesizing the target molecules, the five building blocks 11-15 were tested for their performance in AGA by establishing optimal glycosylation conditions in the context of 
Table 1 Optimized glycosylation conditions for AGA using building blocks $11-15^{a}$

\begin{tabular}{llllll}
\hline Entry & Glycosyl donor & $t_{1}(\mathrm{~min})$ & $T_{1}\left({ }^{\circ} \mathrm{C}\right)$ & $t_{2}(\mathrm{~min})$ & $T_{2}\left({ }^{\circ} \mathrm{C}\right)$ \\
\hline 1 & $\mathbf{1 1}$ & 5 & -20 & 20 & 0 \\
2 & $\mathbf{1 2}$ & 5 & -20 & 20 & 0 \\
3 & $\mathbf{1 3}$ & 5 & -20 & 40 & 0 \\
4 & $\mathbf{1 4}$ & 5 & -35 & 30 & -15 \\
5 & $\mathbf{1 5}$ & 5 & -40 & 20 & -20
\end{tabular}

${ }^{a} t_{1}$ : incubation time, $T_{1}$ : incubation temperature, $t_{2}$ : glycosylation time, $T_{2}$ : glycosylation temperature.

dimer or trimer syntheses (Table 1). All AGA syntheses were executed using an oligosaccharide synthesizer and Merrifield resin equipped with photolabile linker $\mathbf{1 6}$ as solid support. ${ }^{\mathbf{2 6 3 9 , 4 1 , 4 2}}$ After each glycosylation, the temporary protecting group was removed to allow for further chain elongation. In the case of Fmoc, 10 min incubation with $20 \%$ piperidine in DMF was sufficient; Lev was selectively cleaved by treatment with a hydrazine acetate solution $(0.15 \mathrm{M})$, liberating a hydroxyl group for the subsequent glycosylation step. After complete assembly, the desired oligosaccharide was cleaved from the solid support in a continuous flow photoreactor and analyzed by HPLC. ${ }^{39}$

Full conversion and excellent stereoselectivity were achieved for thioglycosides $\mathbf{1 1}$ and $\mathbf{1 2}$ employing eight equivalents of building block and a glycosylation time of $20 \mathrm{~min}$ at $0{ }^{\circ} \mathrm{C}$, after a short incubation (incubation time, $t_{1}$ ) at lower temperatures (Table 1). Glycosylation reagents are added dropwise to the reaction vessel at a controlled incubation temperature $\left(T_{1}\right) \cdot T_{1}$ is typically $20{ }^{\circ} \mathrm{C}$ below the glycosylation temperature $\left(T_{2}\right)$, to minimize reactivity before the reagent delivery process is completed. Afterwards the reaction vessel is warmed up to $T_{2}$ to perform the coupling. Highly reactive perbenzylated fucose $\mathbf{1 5}$ was activated at $-20{ }^{\circ} \mathrm{C}$ to avoid hydrolysis. Glucosamine 13 proved less reactive than the other building blocks and required 40 min glycosylation time to achieve full conversion. Dibutyl phosphate 14 was coupled at $-15{ }^{\circ} \mathrm{C}$ for $30 \mathrm{~min}$ using five equivalents of building block.

Linear hexasaccharide $\mathrm{nLc}_{6} 17$, the unbranched backbone of KH-1 and Le ${ }^{\mathrm{x}}$-dimer, served as a first test for the optimized conditions. HPLC analysis of the crude products after AGA and light-induced cleavage showed that just one product was formed (ESI $\dagger$ ) before protected nLc $_{6}$ was isolated in $55 \%$ yield by preparative HPLC (Fig. 3A).

Next, two branching strategies for Le type-II antigens $\operatorname{Le}^{\mathrm{y}}$, $\mathrm{Le}^{\mathrm{x}}, \mathrm{Le}^{\mathrm{x}}$-dimer and $\mathrm{KH}-1$ were evaluated. After introduction of building block 13 into an oligosaccharide, the Fmoc group can be removed and a galactose can be attached at the $\mathrm{C} 4$ hydroxyl group of GlcN before the Lev at the C3 hydroxyl is cleaved and a fucose is attached; subsequently chain elongation continues ('strategy 1'). Alternatively, this process can be inversed ('strategy 2', Fig. 3B). Both branching strategies were tested

A

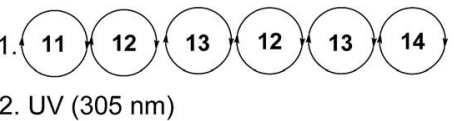

$11,12,13,14,16$

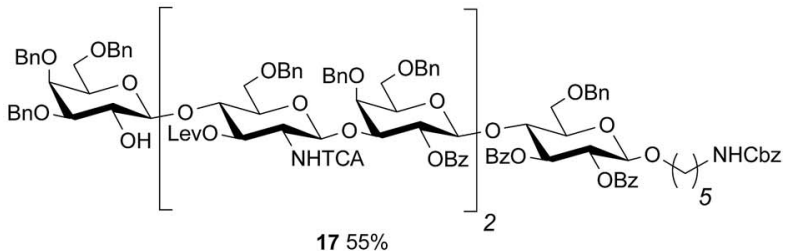

B

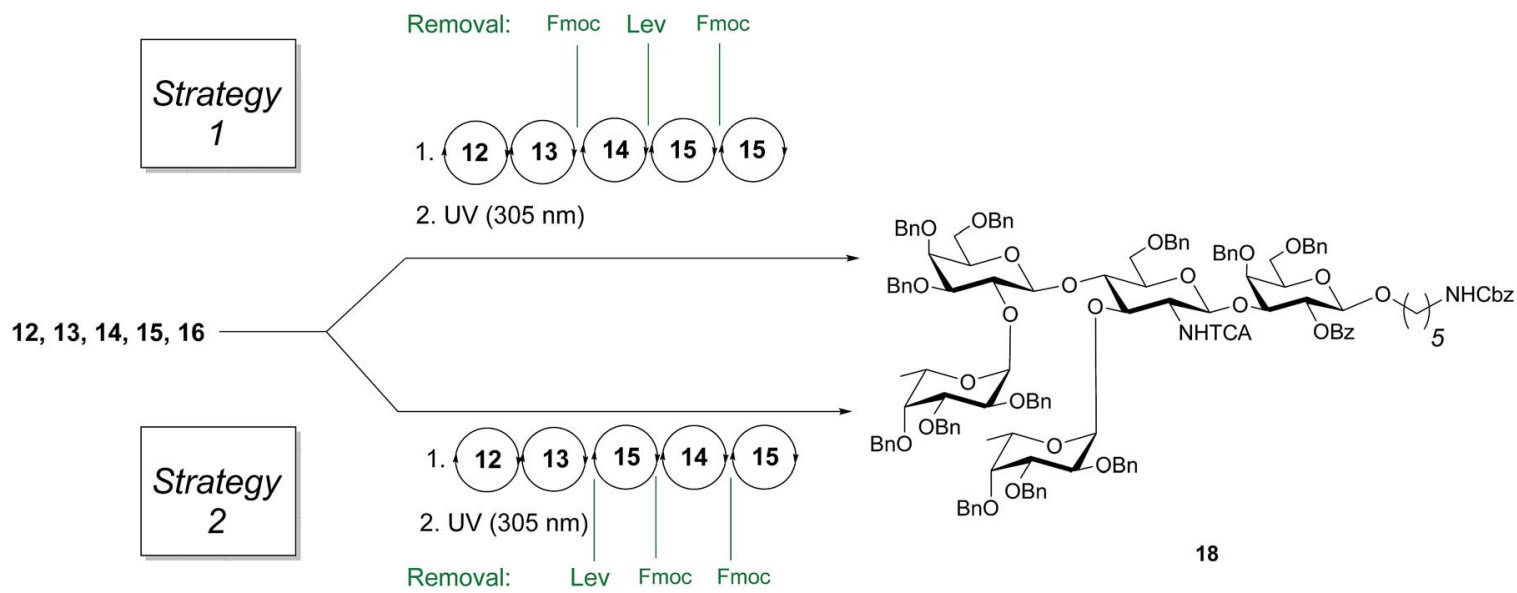

Fig. 3 (A) AGA of fully protected linear hexamer 17 (B) different assembly strategies for the synthesis of 18. Conditions for AGA: (1) 8 equiv. of 11, 12,13 or 15 and $\mathrm{NIS} / \mathrm{TfOH}$ in $\mathrm{DCM} /$ dioxane for $-20^{\circ} \mathrm{C}(5 \mathrm{~min}) \rightarrow 0{ }^{\circ} \mathrm{C}(20 \mathrm{~min}$ or $40 \mathrm{~min})$ or $-40{ }^{\circ} \mathrm{C}(5 \mathrm{~min}) \rightarrow-20^{\circ} \mathrm{C}(20 \mathrm{~min})$, or $14(5 \mathrm{equiv}$ ) and 5 equiv. of TMSOTf in DCM at $-35^{\circ} \mathrm{C}(5 \mathrm{~min}) \rightarrow-15^{\circ} \mathrm{C}$ (30 min). Fmoc removal in $20 \%$ piperidine in DMF at $25^{\circ} \mathrm{C}$ for $10 \mathrm{~min}$. Lev removal in $0.15 \mathrm{M}$ hydrazine in py/AcOH$/ \mathrm{H}_{2} \mathrm{O}$ for $2 \times 30$ min pulsed bubbling. (2) Photocleavage: $h \nu(305 \mathrm{~nm})$. 
A

1. Automated Glycan Assembly

2. UV $(305 \mathrm{~nm})$

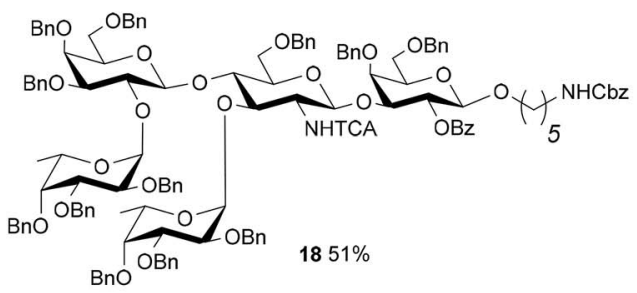

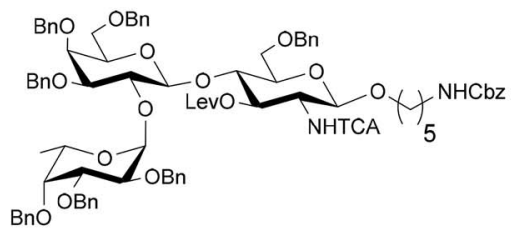

$1957 \%$

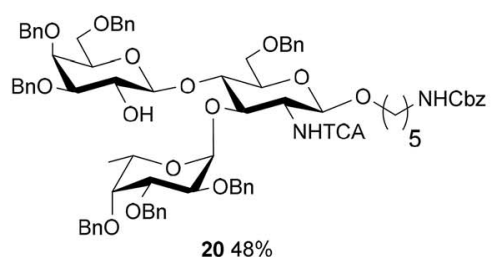

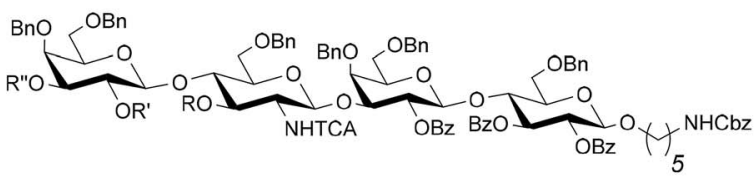

$21 \mathrm{R}=\mathrm{H}, \mathrm{R}^{\prime}=2,3,4-$ tri-O-Bn- $\alpha$-L-Fuc, $\mathrm{R}^{\prime \prime}=\mathrm{Bn} \quad 44 \%$ $22 \mathrm{R}=2,3,4-$ tri-O-Bn- $\alpha$-L-Fuc , R' $=H, R^{\prime \prime}=B n \quad 48 \%$ $23 \mathrm{R}=\mathrm{R}^{\prime}=2,3,4$-tri-O-Bn- $\alpha-$ - -Fuc, $\mathrm{R}^{\prime \prime}=\mathrm{Bn} \quad 65 \%$ $24 \mathrm{R}=\mathrm{Lev}, \mathrm{R}^{\prime}=\mathrm{Bz}, \mathrm{R}^{\prime \prime}=\mathrm{H}$

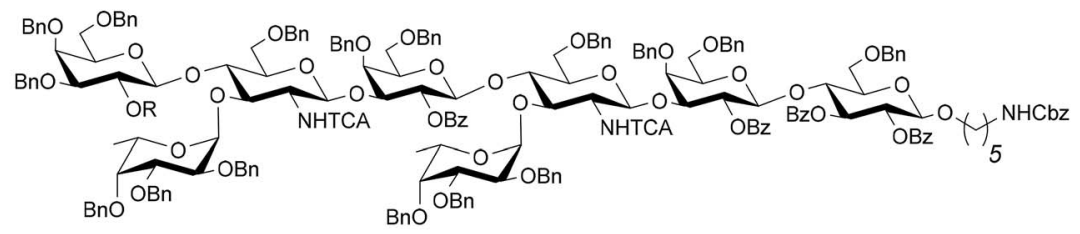

$\begin{array}{ll}25 \mathrm{R}=\mathrm{H} & 28 \% \\ 26 \mathrm{R}=2,3,4 \text {-tri-O-Bn- } \alpha-L-F u c & 28 \%\end{array}$

B

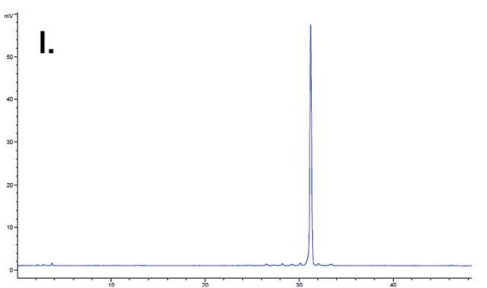

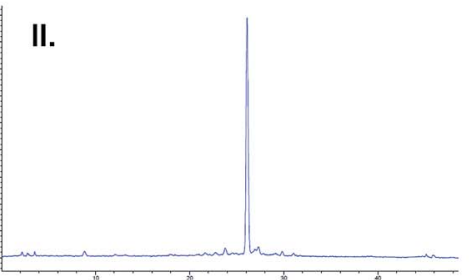

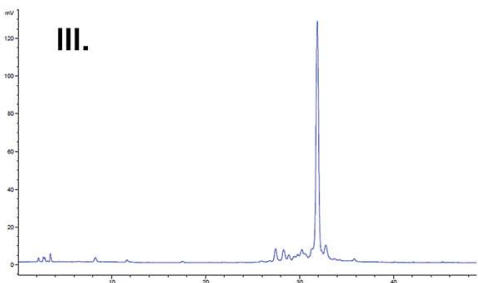

Fig. 4 (A) AGA of fully protected Lewis type-II oligosaccharides. Reaction conditions for the AGA: (1) 8 equiv. of 11, 12, 13 or 15 and NIS/TfOH in $\mathrm{DCM} /$ dioxane for $-20^{\circ} \mathrm{C}(5 \mathrm{~min}) \rightarrow 0{ }^{\circ} \mathrm{C}$ (20 min or $40 \mathrm{~min}$ ) or $-40^{\circ} \mathrm{C}(5 \mathrm{~min}) \rightarrow-20^{\circ} \mathrm{C}(20 \mathrm{~min})$, or 14 (5 equiv.) and 5 equiv. of TMSOTf in DCM at $-35^{\circ} \mathrm{C}$ (5 min) $\rightarrow-15^{\circ} \mathrm{C}$ (30 min). Fmoc removal in $20 \%$ piperidine in DMF at $25^{\circ} \mathrm{C}$ for $10 \mathrm{~min}$. Lev removal in $0.15 \mathrm{M} \mathrm{Hydrazine} \mathrm{in} \mathrm{py/AcOH/}$ $\mathrm{H}_{2} \mathrm{O}$ for $2 \times 30$ min pulsed bubbling. (2) Photocleavage: $h \nu(305 \mathrm{~nm})$. The exact reaction sequences can be found in the ESI. $\dagger$ (B) Analytical NPHPLC of protected oligosaccharides Le 22 (I), Le 23 (II) and KH-1 26 (III) after AGA and photo-induced cleavage from the resin. HPLC was performed using YMC-Pack $5 \mu \mathrm{m}(150 \times 4.6 \mathrm{~mm}$ i.d.), detection by ELSD.

using 18 as a model to ensure that all glycosylation cycles result in full conversion and excellent stereoselectivity. After lightinduced cleavage and preparative HPLC, 18 was isolated in $39 \%$ yield using strategy 1 . Strategy 2 resulted in an improved result as judged by analytical HPLC and 51\% isolated yield.

With a set of building blocks in hand, a series of protected Lewis type-II-chain blood group related antigens 19-26 (28-65\% yield) was synthesized via strategy 2 with excellent stereoselectivity (Fig. 4). The syntheses of 19-24 yielded no significant amounts of deletion sequences. The AGA protocol was adjusted slightly for the extended chain antigens 25 and 26 to achieve full conversion in every glycosylation cycle. Two glycosylation cycles were performed when introducing the second GlcN building block since the GlcN building block is less reactive and the branched acceptor is sterically more hindered (Fig. 4). Antigens 17-26 were assembled using five building blocks. $\mathrm{Le}^{\mathrm{x}}$ and $\mathrm{H}^{-}$ antigen were assembled with the initial lactose unit (21 and 22) or without (19 and 20) to provide access to all variants of these structures for biological studies. ${ }^{43}$ Lewis type-chain ceramides on the surface of human cells carry the initial lactose unit, ${ }^{44}$ while many biological studies only consider the terminal fucosylated epitope. ${ }^{45,46}$ Streamlined coupling cycles rendered the assembly 


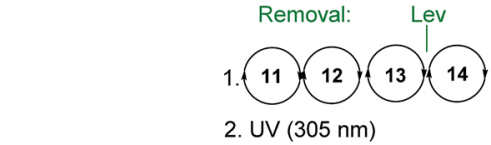

$11,12,13,14,16$

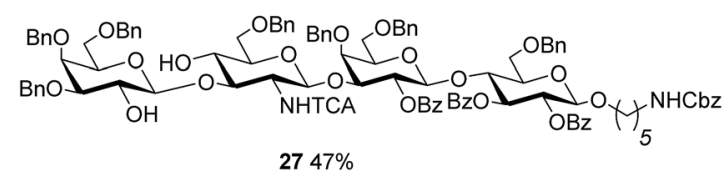

$2747 \%$
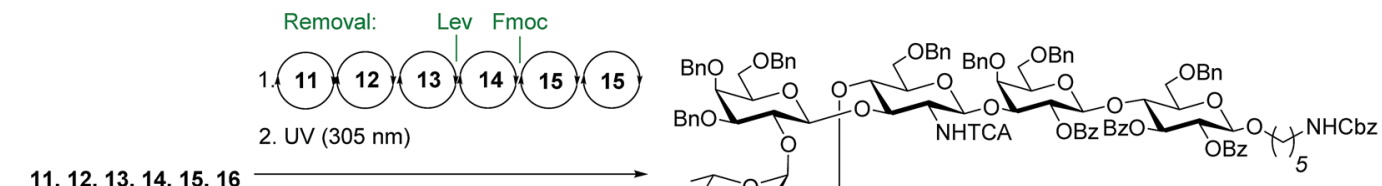

$11,12,13,14,15,16$

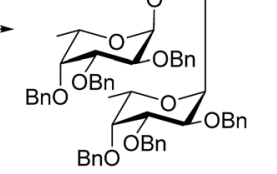

$2834 \%$
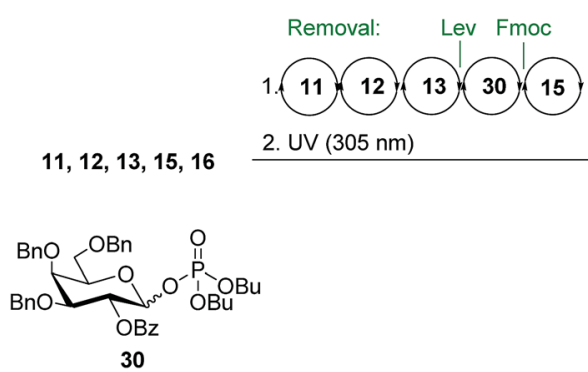

2. UV $(305 \mathrm{~nm})$

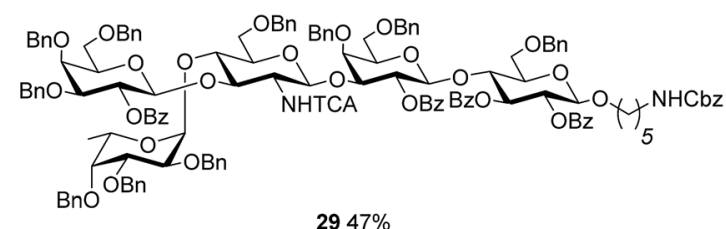

Fig. 5 Syntheses of the protected Lewis type-I chain antigens 27, 28 and 29. Conditions for AGA: (1) 8 eq. of 11, 12, 13 or 15 and NIS/TfOH in $\mathrm{DCM} /$ dioxane for $-20^{\circ} \mathrm{C}(5 \mathrm{~min}) \rightarrow 0{ }^{\circ} \mathrm{C}(20 \mathrm{~min}$ or $40 \mathrm{~min})$ or $-40{ }^{\circ} \mathrm{C}(5 \mathrm{~min}) \rightarrow-20^{\circ} \mathrm{C}(20 \mathrm{~min})$, or 14 or 30 (5 equiv.) and 5 equiv. of TMSOTf in $\mathrm{DCM}$ at $-35^{\circ} \mathrm{C}(5 \mathrm{~min}) \rightarrow-15^{\circ} \mathrm{C}$ (30 min). Fmoc removal in $20 \%$ piperidine in DMF at $25^{\circ} \mathrm{C}$ for $10 \mathrm{~min}$. Lev removal in $0.15 \mathrm{M}$ hydrazine in Py/ $\mathrm{AcOH} / \mathrm{H}_{2} \mathrm{O}$ for $2 \times 30$ min pulsed bubbling. (2) Photocleavage: $h \nu(305 \mathrm{~nm})$.

of KH-1 nonasaccharide 26 ( $15 \mathrm{~h})$ significantly faster than an earlier AGA version that required $23 \mathrm{~h}^{25}$

After preparing all Lewis type-II-chain antigens, we set out to assemble the Lewis type-I-chain antigens Lewis ${ }^{\mathrm{a}}\left(\mathrm{Le}^{\mathrm{a}}, 2\right)$ and $\mathrm{Le}^{\mathrm{b}}$ 3. Both contain a $\beta(1-3)$ instead of a $\beta(1-4)$ linkage between GlcN and the terminal Gal, with the $\mathrm{C} 4 \mathrm{GlcN}$ fucosylated (Fig. 1). Since type-I- and type-II-chain antigens differ only in the substituents attached at the non-reducing end of the GlcN unit, AGA of type-I-chain structures can rely on the sequential cycles developed for type-II chains, as simply the order of Fmoc and Lev cleavage in the GlcN unit has to be inverted. Protected $\mathrm{Lc}_{4}$ tetrasaccharide 27 was obtained in a yield comparable to that for type-II-chain analogue $\mathrm{nLc}_{4}$ (Fig. 5). However, the approach failed to afford branched structures since under these conditions, after $\mathrm{C} 4$ fucosylation of GlcN, Lev was not properly cleaved from the C3 hydroxyl. Therefore, assembly strategies where galactosylation of GlcN precedes Fmoc deprotection and fucosylation were used for the AGA of $\mathrm{Le}^{\mathrm{b}} 28$ and $\mathrm{Le}^{\mathrm{a}} 29$ (Fig. 5).

Replacement of $\mathbf{1 4}$ by 30 that only bears permanent protecting groups allowed for the assembly of $\mathrm{Le}^{\mathrm{a}} \mathbf{2 9}$. A difucosylation strategy, where the Fmoc groups at C2 of galactose 14 and C4 of the GlcN 13 were removed simultaneously furnished 28 (Fig. 5).

Following AGA and photo-induced cleavage from the solid support, all permanent protecting groups have to be removed, to furnish the desired antigens. Global deprotection relied on two steps. Benzoyl groups were cleaved with sodium methoxide in
$\mathrm{MeOH} / \mathrm{DCM}$ as reaction progress was monitored by MALDI. In the second step, benzyl ethers, TCA and the carboxybenzyl group at the amino linker were removed using hydrogenolysis catalyzed by Pd/C to afford the deprotected, $N$-acetylated oligosaccharides. Reversed phase HPLC yielded a series of fully deprotected Lewis antigens 31-38 that carry a C5-amino linker at their reducing end for immobilization on glycan array surfaces or conjugation to carrier proteins (Fig. 6). ${ }^{47,48}$ Rather low isolated yields over the two deprotection steps (17-54\%) may be a result of the poor solubility of partially and fully deprotected glycans during and after deprotection. ${ }^{49}$ In addition, partial cleavage of fucose and TCA was observed. For the extended chain antigens 25 and 26 the combination of methanolysis and hydrogenolysis did not lead to the desired products Le ${ }^{\mathrm{x}}$ dimer (39) and $\mathrm{KH}-1$ (40). Severe solubility issues for the partially-deptrotected oligosaccharides formed during the deprotection process prevented complete hydrogenolysis. Birch reduction followed by peracetylation to facilitate purification was the endgame during the total synthesis of $\mathrm{KH}-1 .^{30}$ This procedure was not applicable as it would result in the irreversible acetylation of the C5-amino linker. Finally, compounds 25 and 26 were deprotected using sodium in liquefied ammonia gas followed by methanolysis. The final oligosaccharides were purified using a Sephadex-G25 column to yield 39 (13\%) and 40 (19\%). The bottleneck of chemical glycan synthesis is the removal of protective groups from the final molecules and is common to AGA and other modes of glycan construction. 


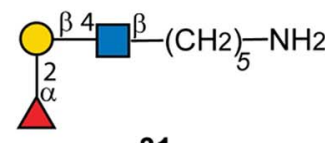

31

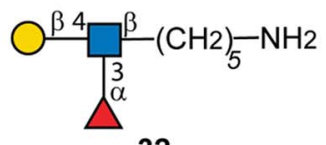

32

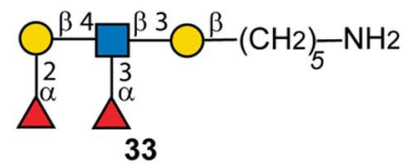

33

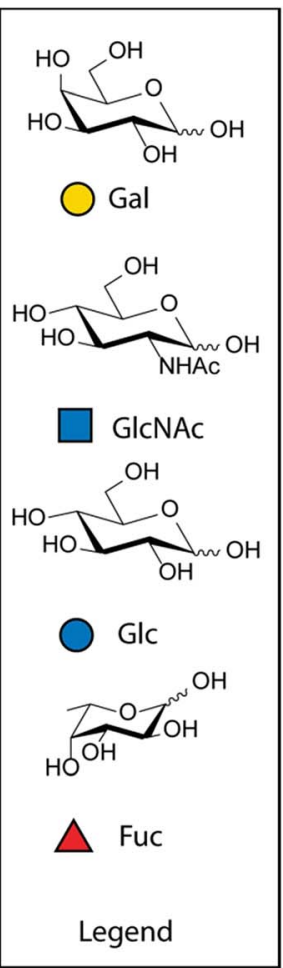

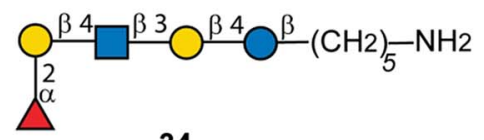

34

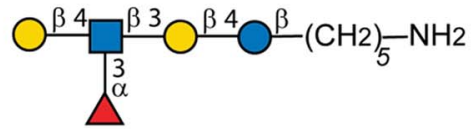

35

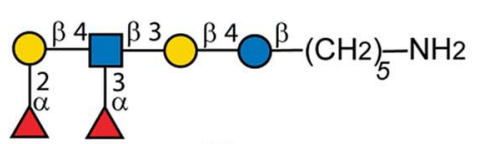

36

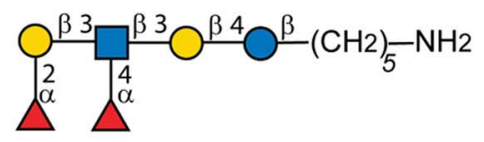

37

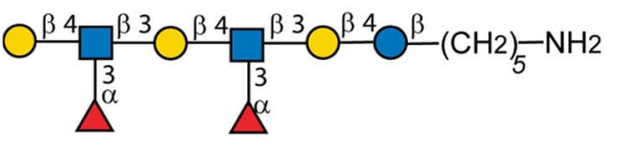

39

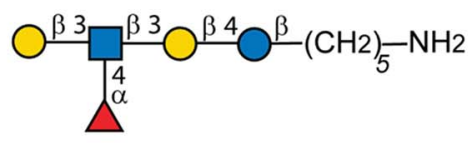

38

Fig. 6 Synthetic Lewis type-I- and type-II-chain antigens 31-40.

Alternatives such as a combination of AGA with enzymatic glycosylations may circumvent deprotection issues but these methods have not yet been established for complex, branched oligosaccharides such as $\mathrm{KH}-1 .{ }^{50,51}$

\section{Conclusions}

A set of Lewis type- I and type-II-chain antigens was synthesized via automated glycan assembly in a fast, reliable and reproducible fashion. Five building blocks were sufficient to synthesize all Lewis type-II antigens including $\mathrm{H}$-antigen II, $\mathrm{Le}^{\mathrm{x}}$, $\mathrm{Le}^{\mathrm{y}}$ and $\mathrm{KH}-1$ and the Lewis type-I-chain-related structures $\mathrm{Lc}_{4}$ and $\mathrm{Le}^{\mathrm{b}}$. For the assembly of $\mathrm{Le}^{\mathrm{a}}$ an additional building block was necessary, since the temporary Lev protecting group was difficult to cleave. Optimized glycosylation cycles led to full conversion and excellent stereoselectivity during AGA and minimized the formation of side products. Global deprotection of the target molecules provided sufficient quantities of the target glycans for biological studies.

\section{Conflicts of interest}

There are no conflicts to declare.

\section{Acknowledgements}

We thank the Max Planck Society for generous financial support. We acknowledge DFG SFB/Transregio 67 for funding to M. G. We are grateful to Dr Maria Spassova for advice concerning the final deprotection of KH-1 and Dr Martina Delbianco for advice concerning the AGA. We thank Dr Kim Lemaihoang for providing the linker-equipped solid support, Eva Settels for maintenance of HPLCs and other analytical devices, and Olaf Niemeyer for support with NMR studies.

\section{Notes and references}

1 C. Green, FEMS Microbiol. Immunol., 1989, 1, 321.

2 H. Schenkel-Brunner, Human Blood Groups, Springer-Verlag Wien, Vienna, 2000.

3 A. C. Fitchette, M. Cabanes-Macheteau, L. Marvin, B. Martin, B. Satiat-Jeunemaitre, V. Gomord, K. Crooks, P. Lerouge, L. Faye and C. Hawes, Plant Physiol., 1999, 121, 333.

4 T. Feizi, Curr. Opin. Struct. Biol., 1993, 3, 701.

5 Z. M. Zhu, N. Kojima, M. R. Stroud, S. I. Hakomori and B. A. Fenderson, Biol. Reprod., 1995, 52, 903.

6 T. Boren, P. Falk, K. Roth, G. Larson and S. Normark, Science, 1993, 262, 1892.

7 P. Huang, T. Farkas, W. Zhong, M. Tan, S. Thornton, A. L. Morrow and X. Jiang, J. Virol., 2005, 79, 6714.

8 S.-i. Hakomori, Biochim. Biophys. Acta, Gen. Subj., 1999, 1473, 247.

9 S.-i. Hakomori, The Molecular Immunology of Complex Carbohydrates -2 , ed, A. M. Wu, Springer US, Boston, MA, 2001, pp. 369-402.

10 S. Hakomori, Cancer Res., 1985, 45, 2405. 
11 C. H. Kuo, P. K. Chen, B. I. Chang, M. C. Sung, C. S. Shi, J. S. Lee, C. F. Chang, G. Y. Shi and H. L. Wu, Blood, 2012, 119, 1302.

12 L. Yan, B. Lin, L. Gao, S. Gao, C. Liu, C. Wang, Y. Wang, S. Zhang and M. Iwamori, Int. J. Mol. Sci., 2010, 11, 4441.

13 E. Dabelsteen, J. Pathol., 1996, 179, 358.

14 J. Heimburg-Molinaro, M. Lum, G. Vijay, M. Jain, A. Almogren and K. Rittenhouse-Olson, Vaccine, 2011, 29, 8802.

15 Y. Fukushi, S. I. Hakomori and T. Shepard, J. Exp. Med., 1984, 160, 506.

16 S. Hakomori, E. Nudelman, S. B. Levery and R. Kannagi, J. Biol. Chem., 1984, 259, 4672.

17 R. E. O'Cearbhaill, G. Ragupathi, J. L. Zhu, Q. Wan, S. Mironov, G. B. Yang, M. K. Spassova, A. Iasonos, S. Kravetz, O. Ouerfelli, D. R. Spriggs, S. J. Danishefsky and P. J. Sabbatini, Cancers, 2016, 8, 46.

18 P. J. Sabbatini, G. Ragupathi, C. Hood, C. A. Aghajanian, M. Juertzka, A. Lasonos, M. L. Hensley, M. K. Spassova, O. Ouerfelli, D. R. Spriggs, W. P. Tew, J. Konner, H. Clausen, N. Abu Rustum, S. J. Dansihefsky and P. O. Livingston, Clin. Cancer Res., 2007, 13, 4170.

19 M. K. Spassova, W. G. Bornmann, G. Ragupathi, G. Sukenick, P. O. Livingston and S. J. Danishefsky, J. Org. Chem., 2005, 70, 3383.

20 G. Ragupathi, P. P. Deshpande, D. M. Coltart, H. M. Kim, L. J. Williams, S. J. Danishefsky and P. O. Livingston, Int. J. Cancer, 2002, 99, 207.

21 R. Niemelä, J. Natunen, L. Penttilä, H. Salminen, J. Helin, H. Maaheimo, C. E. Costello and O. Renkonen, Glycobiology, 1999, 9, 517.

22 K. O. Lloyd, Glycoconjugate J., 2000, 17, 531.

23 I. M. Ryzhov, E. Y. Korchagina, A. B. Tuzikov, I. S. Popova, T. V. Tyrtysh, G. V. Pazynina, S. M. Henry and N. V. Bovin, Carbohydr. Res., 2016, 435, 83.

24 V. Kamath, J. Sadowska, S. Nilar, D. R. Bundle and O. Hindsgaul, Synlett, 2003, 1327.

25 K. Routenberg Love and P. H. Seeberger, Angew. Chem., Int. Ed., 2004, 43, 602.

26 H. S. Hahm, C.-F. Liang, C.-H. Lai, R. J. Fair, F. Schuhmacher and P. H. Seeberger, J. Org. Chem., 2016, 81, 5866.

27 P. K. Mandal and W. B. Turnbull, Carbohydr. Res., 2011, 346, 2113.

28 O. Blixt and T. Norberg, J. Org. Chem., 1998, 63, 2705.

29 Q. Li and Z. Guo, Org. Lett., 2017, 19, 6558.
30 P. P. Deshpande and S. J. Danishefsky, Nature, 1997, 387, 164.

31 R. Bommer, W. Kinzy and R. R. Schmidt, Liebigs Ann. Chem., 1991, 1991, 425.

32 O. J. Plante, E. R. Palmacci and P. H. Seeberger, Science, 2001, 291, 1523.

33 A. Geert Volbeda, J. van Mechelen, N. Meeuwenoord, H. S. Overkleeft, G. A. van der Marel and J. D. C. Codée, J. Org. Chem., 2017, 82, 12992.

34 H. S. Hahm, M. K. Schlegel, M. Hurevich, S. Eller, F. Schuhmacher, J. Hofmann, K. Pagel and P. H. Seeberger, Proc. Natl. Acad. Sci. U. S. A., 2017, 114, E3385.

35 P. H. Seeberger, Acc. Chem. Res., 2015, 48, 1450.

36 K. Naresh, F. Schuhmacher, H. S. Hahm and P. Seeberger, Chem. Commun., 2017, 53, 9058.

37 S. Marionneau, A. Cailleau-Thomas, J. Rocher, B. Le Moullac-Vaidye, N. Ruvoën, M. Clément and J. Le Pendu, Biochimie, 2001, 83, 565.

38 M. W. Weishaupt, H. S. Hahm, A. Geissner and P. H. Seeberger, Chem. Commun., 2017, 53, 3591.

39 S. Eller, M. Collot, J. Yin, H. S. Hahm and P. H. Seeberger, Angew. Chem., Int. Ed., 2013, 52, 5858.

40 H. Satoh, H. S. Hansen, S. Manabe, W. F. van Gunsteren and P. H. Hünenberger, J. Chem. Theory Comput., 2010, 6, 1783.

41 O. Calin, S. Eller and P. H. Seeberger, Angew. Chem., Int. Ed., 2013, 52, 5862.

42 J. Kandasamy, F. Schuhmacher, H. S. Hahm, J. C. Klein and P. H. Seeberger, Chem. Commun., 2014, 50, 1875.

43 V. Fournière, L. Skantz, F. Sajtos, S. Oscarson and M. Lahmann, Tetrahedron, 2010, 66, 7850.

44 S.-i. Hakomori, Biochim. Biophys. Acta, Gen. Subj., 2008, 1780, 325-346.

45 J. Hofmann, A. Stuckmann, M. Crispin, D. J. Harvey, K. Pagel and W. B. Struwe, Anal. Chem., 2017, 89, 2318.

46 B. Fiege, C. Rademacher, J. Cartmell, P. I. Kitov, F. Parra and T. Peters, Angew. Chem., Int. Ed., 2012, 51, 928.

47 A. Geissner and P. H. Seeberger, Annu. Rev. Anal. Chem., 2016, 9, 223.

48 X. Wu, C.-C. Ling and D. R. Bundle, Org. Lett., 2004, 6, 4407. 49 Y. Yu, S. Gim, D. Kim, Z. A. Arnon, E. Gazit, P. H. Seeberger and M. Delbianco, J. Am. Chem. Soc., 2019, 141, 4833.

50 R. J. Fair, H. S. Hahm and P. H. Seeberger, Chem. Commun., 2015, 51, 6183.

51 T. Li, M. Huang, L. Liu, S. Wang, K. W. Moremen and G.-J. Boons, Chem.-Eur. J., 2016, 22, 18742. 